\title{
Rapid scan FTIR reveals propane (am)oxidation mechanisms over Vanadium based
} catalysts

\author{
M. Olga Guerrero-Pérez ${ }^{1,2}$, Alan J. McCue ${ }^{1}$, James A. Anderson ${ }^{1}$ \\ ${ }^{1}$ Surface Chemistry and Catalysis Group, Department of Chemistry, University of Aberdeen, \\ Meston Walk, AB24 3UE, Aberdeen (UK). ${ }^{2}$ Departamento de Ingeniería Química, Universidad \\ de Málaga, E29071, Málaga (Spain)
}

Keywords: Rapid-Scan Operando IR, Sb-V-O, propane, ammoxidation, partial oxidation

\begin{abstract}
Rapid scan FTIR coupled with Mass Spectrometry (MS) has been used to determine the role of spectroscopically observed species in the reaction media during propane dehydrogenation over a V/Al catalyst, and propane ammoxidation on a Sb-V-O sample. During the propane dehydrogenation reaction, it was shown that oxygenates are not formed during the first minutes and propylene is formed directly from propane via dehydrogenation on a V-O site. Oxygenates may form though secondary reactions due to further propylene oxidation. Propane dehydrogenation is the first step during the propane ammoxidation reaction. This is followed by the transformation of propylene into acrylonitrile, which is the rate limiting step. Rapid scan FTIR/MS is shown to be a useful technique for monitoring chemical reactions in order to identify or eliminate observed surface species as potential reaction intermediates. Understanding of the reaction mechanism is necessary in order to improve the chemical process design and the catalytic material.
\end{abstract}

\section{Introduction}

During the last decades, there has been considerable effort from both a fundamental scientific and industrial perspective, for developing catalytic materials which are able to transform alkanes (in place of C1-C4 alkenes) into commodity chemicals $\left({ }^{1},{ }^{3}, 3\right)$. The accessibility of natural gas from both fracking and shale has increased the availability of alkanes. Propane is subsequently a convenient feedstock for the industrial synthesis of oxygenates such as acrolein or acrylic acid $\left({ }^{4},{ }^{5}\right)$, as well as nitriles as acrylonitrile $\left({ }^{6}\right)$ which are already produced from propylene. Propane based commercial processes would decrease the production costs considerably $\left({ }^{7}\right)$, since historically propane has been less expensive than propylene. Due to that, Asahi Chemical constructed a new propane ammoxidation plant using propane instead of propylene ten years ago although that technology has not replaced the old propylene based technology (7). A recent paper (7) made an analysis of the market based on different scenarios, concluding that propane ammoxidation technology only would replace a propylene based process when the catalysts were able to provide a high acrylonitrile yield using the existing plants, in order to also reduce the capital costs. Such analysis (7) estimated that the current yield of about 58\% to acrylonitrile has to be increased to $70 \%$ in order to make the propane based technology commercially attractive. This data underlines the importance of developing new and improved catalytic materials for this process. In order to achieve this, it is necessary to understand the key active centers and the reaction mechanisms to guide rational catalyst design. Another option that has been proposed is avoiding the use of fossil based starting materials altogether. Although the production of oxygenates and nitriles has been described through a bio-based route $\left({ }^{8},{ }^{10},{ }^{11},{ }^{12}\right)$, the low availability of bio-based feedstocks as well as high production costs, mean biobased processes are far from commercial implementation $\left({ }^{13},{ }^{14}\right)$, although the alkane-based processes appears to be the most desirable approach. Propane is also a good option for the production of propylene, the demand of which is predicted to increase in the near future. The oxidative dehydrogenation (ODH) of propane to obtain propylene is an attractive alternative to replace the high-energy demanding steam cracking $\left({ }^{15}\right)$. Indeed, several groups are working intensely in this area to develop the adequate catalysts to activate the propane molecule $\left({ }^{16},{ }^{17}, 18\right)$. In the case of propane ammoxidation, the catalytic materials that have been reported for propane ODH are still far from commercial implementation (15). Therefore, developing catalytic processes for the transformation of propane into propylene oxygenates and nitriles is of major importance for the chemical industry in order to continue producing valuable goods with efficiency in terms of the use of energy and raw materials (7).

Vanadium oxide materials are well-known for their oxidative catalytic properties $\left({ }^{19},{ }^{20}\right)$; because their $\mathrm{V}$ atoms can adopt several formal oxidation states (ranging from $2^{+}$to $5^{+}$) they are used as redox catalysts $\left({ }^{21}\right)$ and widely used in partial oxidation processes $\left({ }^{22}\right)$. The redox properties of these materials also make them useful for other applications such as Li-ion batteries, gas sensors, supercapacitors and other 
electronic devices $\left({ }^{23}\right)$. For propane ammoxidation reaction, it has been shown that the $\mathrm{V}$ sites are active for propane activation, but they are not able to insert the $\mathrm{N}$ atom to form the nitrile, meaning they are unselective to acrylonitrile formation $\left({ }^{24}\right)$. Subsequently, efficient propane ammoxidation catalysts are based on vanadium mixed oxides with antimony $\left({ }^{25},{ }^{26}\right)$ or with molybdenum $\left({ }^{27},{ }^{28}\right)$.

Due to the importance of propane partial oxidation reactions and the necessity of improving the catalytic materials for their commercial implementation, research efforts have been focused on uncovering the reaction mechanisms of alkane partial oxidation reactions over vanadium-based catalysts. The knowledge of the active species and of the mechanisms, would allow a rational design of the catalytic materials and it is also a key stage in improving these catalytic processes. Most studies indicate that propylene is the main intermediate formed during propane ammoxidation to acrylonitrile $\left({ }^{29},{ }^{30}\right)$ and that it is formed on a V site by dehydrogenation of the propane molecule, which is also the first step during propane ODH. However, the role of oxygenates in both propane oxydehydrogenation and ammoxidation is unclear, as well as the formation of sub-products that adsorb on the surface of catalysts, which in some cases may lead to deactivation. Further research effort is therefore necessary to clarify these important issues.

FTIR is a commonly used characterization technique for catalytic materials as it allows the identification of adsorbed species on the surface of catalysts, analysis of the catalytic structure, as well as analysis of the gas phase. The rapid scan operando technology $\left({ }^{31}\right)$ allows the monitoring within a millisecond time frame and has been demonstrated to be a technique of special relevance for the study of catalytic materials. With the objective of elucidating the reaction mechanism of propane oxidation and ammoxidation reactions over V-Sb-O, rapid scan FTIR technique has been adapted herein with the aim of developing a fundamental understanding of the important processes that would allow the rational design of partial oxidation catalytic processes.

\section{Experimental}

\section{Catalytic materials}

The supported V-Sb-O alumina catalysts was prepared by initially dissolving the required amount of antimony acetate (Aldrich) in tartaric acid (Sigma, 0.3 M), following a procedure already described $\left({ }^{32}\right)$. It was stirred until all the $\mathrm{Sb}$ was dissolved and then vanadium metavanadate (Sigma) and alumina (Girdler Südchemie) were added. The same procedure was followed but with only the addition of metavanadate for the synthesis of $\mathrm{V}-\mathrm{O}$ alumina supported sample. Both suspensions were dried in a rotary evaporator before the resulting solid was dried further at $115^{\circ} \mathrm{C}$ for $24 \mathrm{~h}$ and calcined $400^{\circ} \mathrm{C}$ for $4 \mathrm{~h}$. The total coverage of $\mathrm{V}+\mathrm{Sb}$ or $\mathrm{V}$ was 9 atoms per square nanometer, in accordance with previous characterization studies on alumina that indicated that this is the maximum amount of VOx units that remain dispersed on the alumina before crystalline $\mathrm{V}_{2} \mathrm{O}_{5}$ oxide forms $(7,20)$. The in situ Raman spectra of Sb-V-O and V-O alumina supported samples under dehydrated conditions (24) indicated that VOx species are dispersed in both cases, since $\mathrm{V}_{2} \mathrm{O}_{5}$ was not detected. In addition to dispersed $\mathrm{VOx}, \mathrm{VSbO}_{4}$ rutile phase was identified in Sb-V-O sample by Raman spectroscopy (24).

\section{Rapid-scan operando FTIR experiments}

Rapid-scan operando DRIFTS experiments were performed by using a Shimadzu FTIR (IR Tracer 100) equipment with a Harrick reaction cell, that was connected to an on line EcoSys-P mass spectrometer for analysis of the effluents. Analysis were made using sample with particle dimensions in the 0.25-0.125 $\mathrm{mm}$ range. Feed gases were controlled through the use of mass flow controllers and fed via a valve that permitted the gas mixture to be changed; by this way, it was possible to change the feed gases from air to reaction mixture whilst monitoring the spectroscopic impact by Rapid-scan operando FTIR on a second or millisecond timescale. The total flow rate was $50 \mathrm{ml} / \mathrm{min}$ with a feed composition close to $25 \% \mathrm{O}_{2}, 9.8$ $\%$ propane and $8.6 \%$ ammonia, that was selected in a previous study (30) as optimum for these catalytic materials and contact time conditions (around $3000 \mathrm{~h}^{-1}$ ). An additional six-way valve with a $1 \mathrm{uL}$ loop, allowed the introduction of a pure gas pulse in the reaction feed. This was used to study the ammoxidation reaction, since pulses of propane were injected in a $50 \mathrm{ml} / \mathrm{min} \mathrm{NH}_{3} /$ air flow. Scheme 1 shows the experimental system set up. 


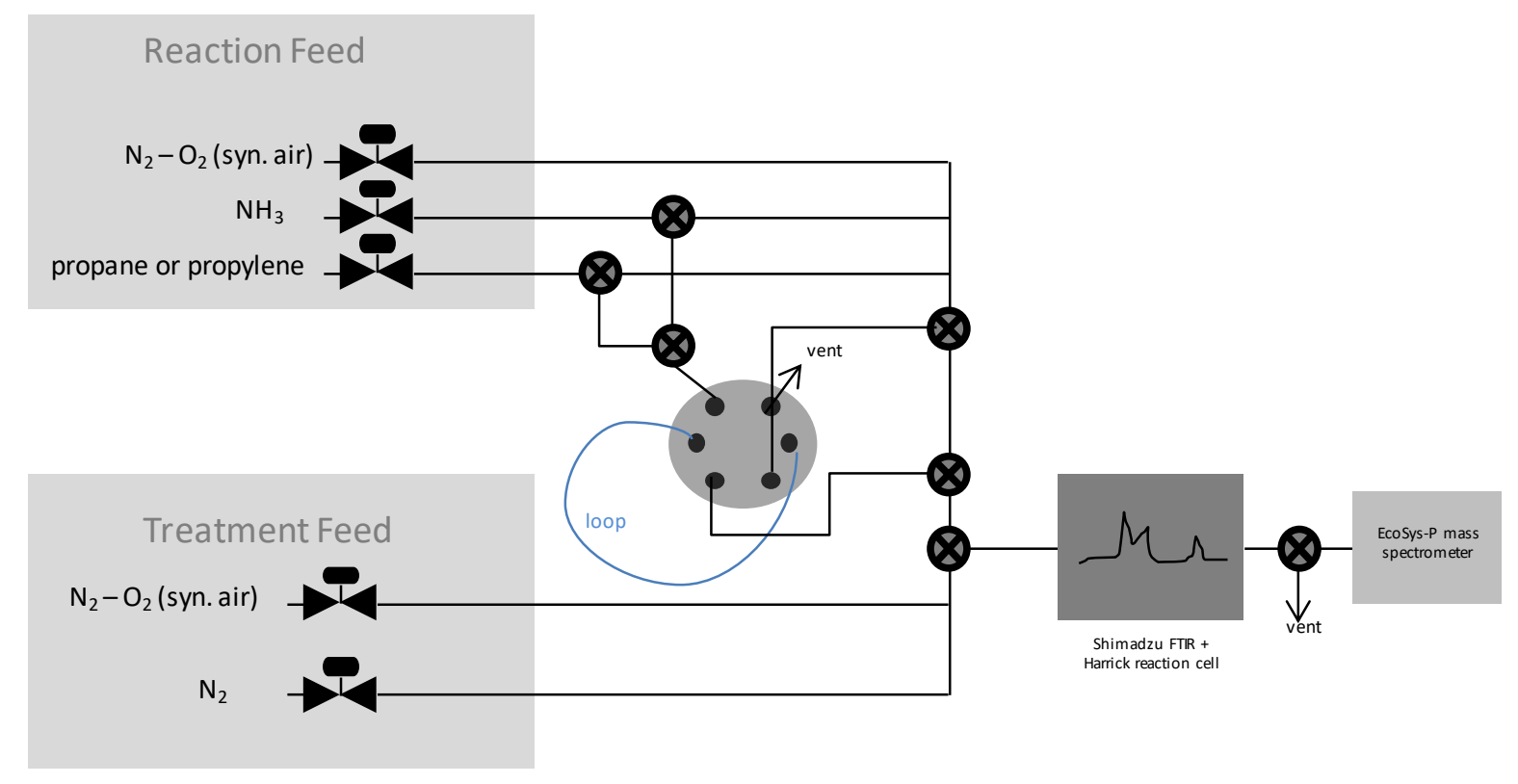

Scheme 1. Experimental set up.

\section{Results and Discussion}

\section{Oxidation of propane over V/Al catalyst}

DRIFTS spectra obtained at steady state conditions for each temperature during both propane and propylene oxidative dehydrogenation $(\mathrm{ODH})$ conditions are shown in Figure 1. The spectrum at ambient conditions for propane shows the characteristic bands of adsorbed propane, with broad bands in the 2800$3000 \mathrm{~cm}^{-1}$ region, assigned to $\mathrm{C}-\mathrm{H}$ stretching modes, and weaker bands near 1470 and $1445 \mathrm{~cm}^{-1}$, characteristics of $-\mathrm{CH}_{2}$ scissor vibrations. As expected, when the temperature is increased, these propane bands decrease, whereas the characteristic bands of $\mathrm{CO}_{2}$ in the $2340 \mathrm{~cm}^{-1}$ region are visible, which indicates that the oxidation reaction is taking place at $400^{\circ} \mathrm{C}$. At higher temperatures, the propane bands decrease again since the extent of the oxidation reaction is higher. When the temperature was increased up to $400^{\circ} \mathrm{C}$, two bands become evident at 1471 and $1562 \mathrm{~cm}^{-1}$. These bands have been previously reported by other authors during propane ODH studies with DRIFTS. More specifically, Airaksinen and co-workers $\left({ }^{33}\right)$ reported the formation of both bands under propane ODH conditions over chromia/alumina catalysts and assigned them to acetates or other carboxylate species. They concluded that these acetate/carboxylate species were formed during side reactions. For example, through the reaction of propane with surface $-\mathrm{OH}$ groups of the support, and suggested that the main propane ODH reaction proceeds through an isopropoxide intermediate that is formed when the propane adsorbs on a VO-Support site, via hydrogen abstraction. They also performed an in situ Raman study that confirmed the formation of coke deposits under these conditions, reporting that the dehydrogenation of propane resulted in the side reaction formation of unsaturated/aromatic, and graphite-like hydrocarbon deposits that deactivate the catalyst. In line with this work, there are more studies that conclude that isopropoxide is the intermediate $\left({ }^{34},{ }^{34}, 35\right)$, that forms upon propane adsorption, with this species then evolving into oxygenates or to propylene, whereas COx would come from further oxidation of both (Scheme 2). The bands near 1471 and $1562 \mathrm{~cm}^{-1}$ were also detected by Deo et al $\left(^{36}\right)$ during propane ODH DRIFTS experiments over $\mathrm{V} / \mathrm{TiO}_{2}$ catalysts, in line with the previous report by Airaksinen. They assigned the bands to oxygenated compounds and showed that two pathways were possible from the intermediate isopropoxide. One directly to propylene product and another to side reactions forming acetate, formate, ketones, aldehydes, and cyclic anhydride adsorbed species. This is in agreement with a recent study performed by simultaneous transmission FTIR and Raman spectroscopy, during propane ODH reaction over $\mathrm{V}$ based catalysts $\left({ }^{37}\right)$. There is also another opinion, since the bands at 1470 and $1445 \mathrm{~cm}^{-1}$ were also detected by Gong et al. $\left({ }^{38}\right)$ during DRIFTS studies under propane ODH conditions with V/Al catalysts. They described that after evacuation, the bands remained unchanged, indicating that they must correspond to strongly adsorbed species. In that paper, they assigned the bands to $\mathrm{C}-\mathrm{H}$ and $\mathrm{C}=\mathrm{O}$ vibrations, and indicated that they had to belong to propane ODH reaction intermediates. These bands 
were not due to coke and the isopropoxide (that forms when propane adsorbs on a $\mathrm{V}$-O-Al site) cannot be the intermediate, concluding that vanadium propenal was the main intermediate, and responsible for the two bands.

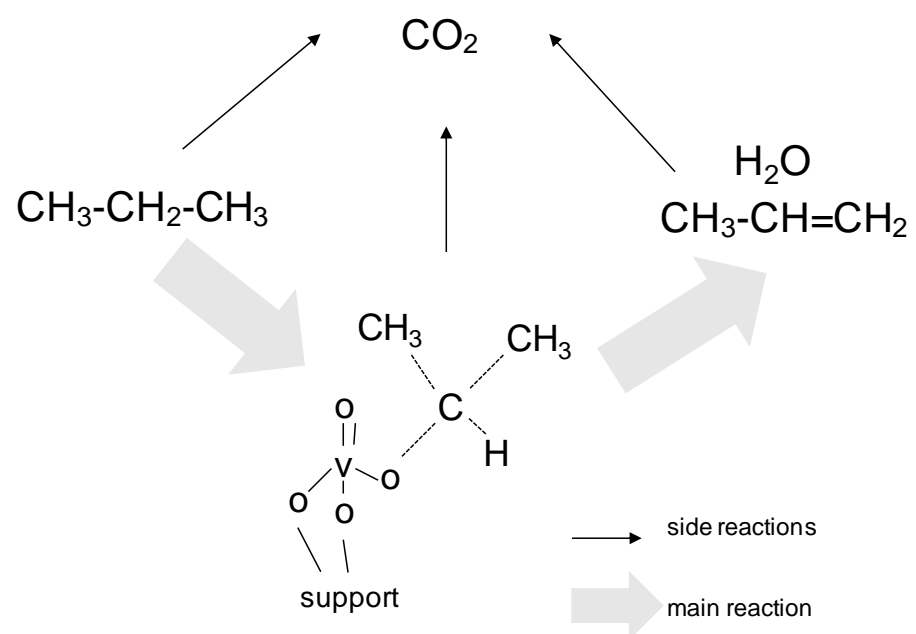

Scheme 2. Main primary intermediate during propane ODH observed during rapid scan FTIR experiments

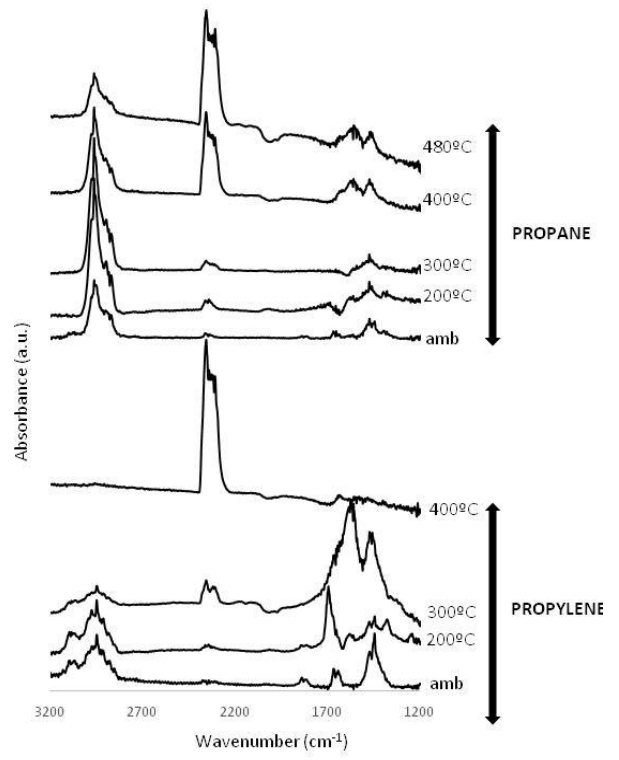

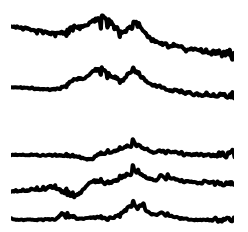

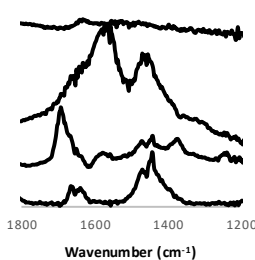

Figure 1. DRIFTS spectra (A) of V/Al sample recorded at propane or propylene conditions (20\% hydrocarbon in air) at different temperatures. A background spectrum recorded in air was subtracted. Figure 1B shows an enlargement of the same spectra in the $1200-1800 \mathrm{~cm}^{-1}$ region.

As described, in the literature there are two explanations for the assignment of the bands that appears under propane ODH conditions (1470 and $1560 \mathrm{~cm}^{-1}$ ), since they can be intermediates, or side products/coke. To clarify this, the first seconds of the propane ODH reaction were followed with rapid scan FTIR. The results are shown in Figure 2A which represents the spectra collected during the first minutes after the feed was changed from air to propane/air at $\mathrm{t}=0$ at $400^{\circ} \mathrm{C}$. During the first milliseconds, the bands corresponding to propane/propylene and $\mathrm{CO}_{2}$ appear. This is accompanied by the detection of propylene, $\mathrm{CO}_{2}$ and water by mass spectrometry (Figure 2B), indicating that the formation of propylene and $\mathrm{CO}_{2}$ is very fast, although importantly the two bands near 1470 and $1560 \mathrm{~cm}^{-1}$ are not detected. This indicates that these bands cannot be related with the intermediate during propylene formation. The same experiment was performed at $480^{\circ} \mathrm{C}$, in this case the amount of propylene, $\mathrm{CO}_{2}$ and water detected in the effluent was higher, indicative of increasing conversion, but again the bands near 1470 and $1560 \mathrm{~cm}^{-1}$ were not detected. 


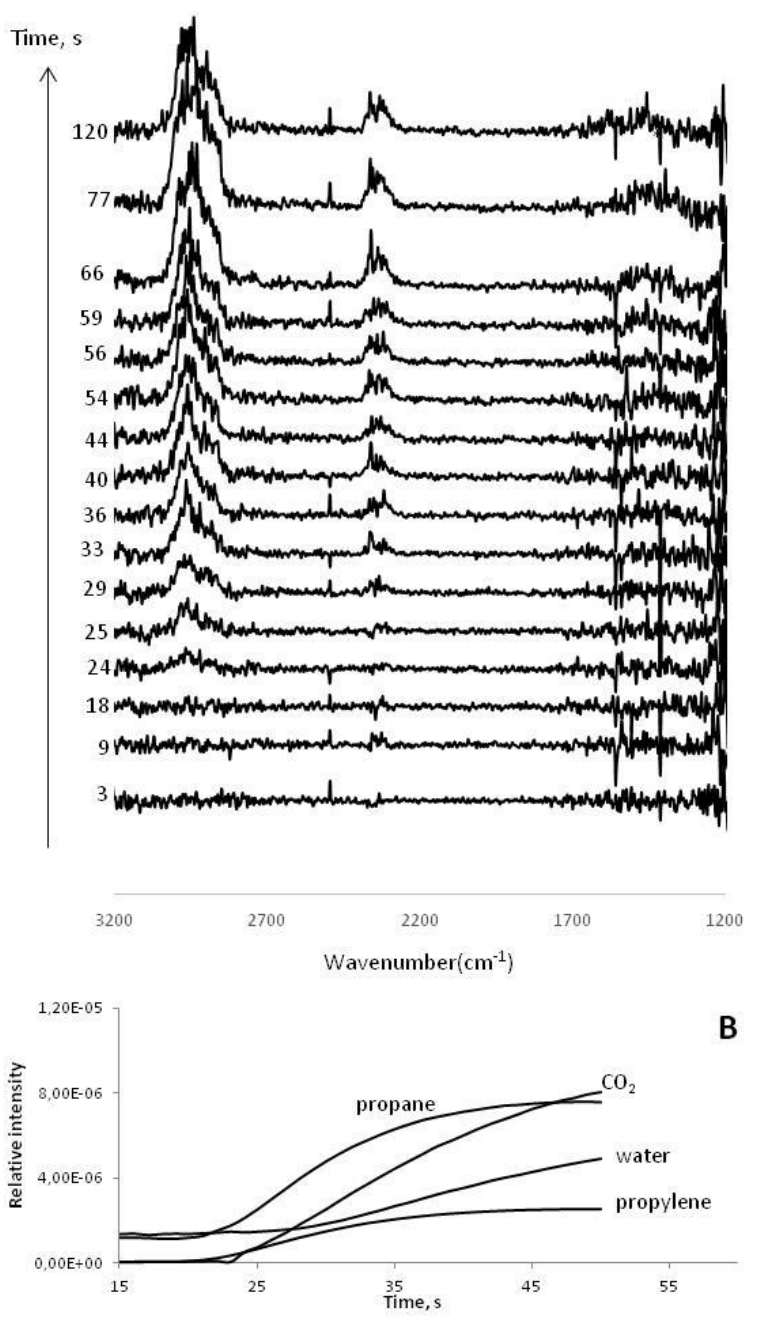

Figure 2A. Rapid scan spectra of V/Al sample at $400^{\circ} \mathrm{C}$ immediately after the feed is changed from air to $20 \%$ propane/air. Numbers in the Figure indicate time in seconds after the change in the gas feed. Figure 2B represents the M.S. signals (FFT filtering was used for smoothing) for propane $(\mathrm{m} / \mathrm{e}=29)$, propylene $(\mathrm{m} / \mathrm{e}=41), \mathrm{CO}_{2}(\mathrm{~m} / \mathrm{e}=44)$ and water $(\mathrm{m} / \mathrm{e}=18)$ during the same experiment, $\mathrm{O}_{2}$ and $\mathrm{N}_{2}$ mass fragments are out of scale as presented.

Figure 1 shows the DRIFTS spectra during steady state propylene oxidation conditions at different temperatures. At ambient temperature, the spectrum is characteristic of adsorbed propylene, with bands in the 2800-3000 $\mathrm{cm}^{-1}$ region due to asymmetrical stretching of $\mathrm{CH}_{3^{-}}$and $-\mathrm{CH}_{2^{-}}$groups, and the symmetrical bending of $-\mathrm{CH}_{3}$ near $1460 \mathrm{~cm}^{-1}$. At $200^{\circ} \mathrm{C}$, the bands of propylene are still visible but a band near $1710 \mathrm{~cm}^{-1}$ could indicate that propylene is partially oxidized into a carboxylic acid. At $300^{\circ} \mathrm{C}$ bands near 1470 and $1545 \mathrm{~cm}^{-1}$ appear in the same positions as observed during the propane oxidation, indicating that they form during both propane and propylene oxidation, which could indicate that they are related with the propylene oxidation instead of propane dehydrogenation into propylene. At $400^{\circ} \mathrm{C}$, all propylene was oxidized to $\mathrm{CO}_{2}$ and the bands were no longer visible. Rapid scan experiments during the first seconds of the propylene oxidation are shown in Figure $3 \mathrm{~A}$, in which $\mathrm{t}=0$ represents the time at which the feed was changed from air to propylene/air. These spectra show the formation of species giving rise to bands near 1470 and $1545 \mathrm{~cm}^{-1}$, with the latter appearing after ca. two seconds, whereas the one near $1470 \mathrm{~cm}^{-1}$ appears at ca., 3 minutes. After running propylene oxidation on this sample, the feed was changed again to air (Figure 3B) which shows that the bands remain clearly visible and that the species responsible for these bands are strongly adsorbed. Indeed, calcination at higher temperatures is required to remove them, in line with the experiments previously described (39) over chromia/alumina catalysts. Subsequently, the experiments with propylene oxidation have demonstrated that the species that have been assigned in the literature to a propanal intermediate (44) during the propane transformation into propylene, may be spectator species formed during the further oxidation of the propylene that remain adsorbed on the surface of vanadium catalysts. 

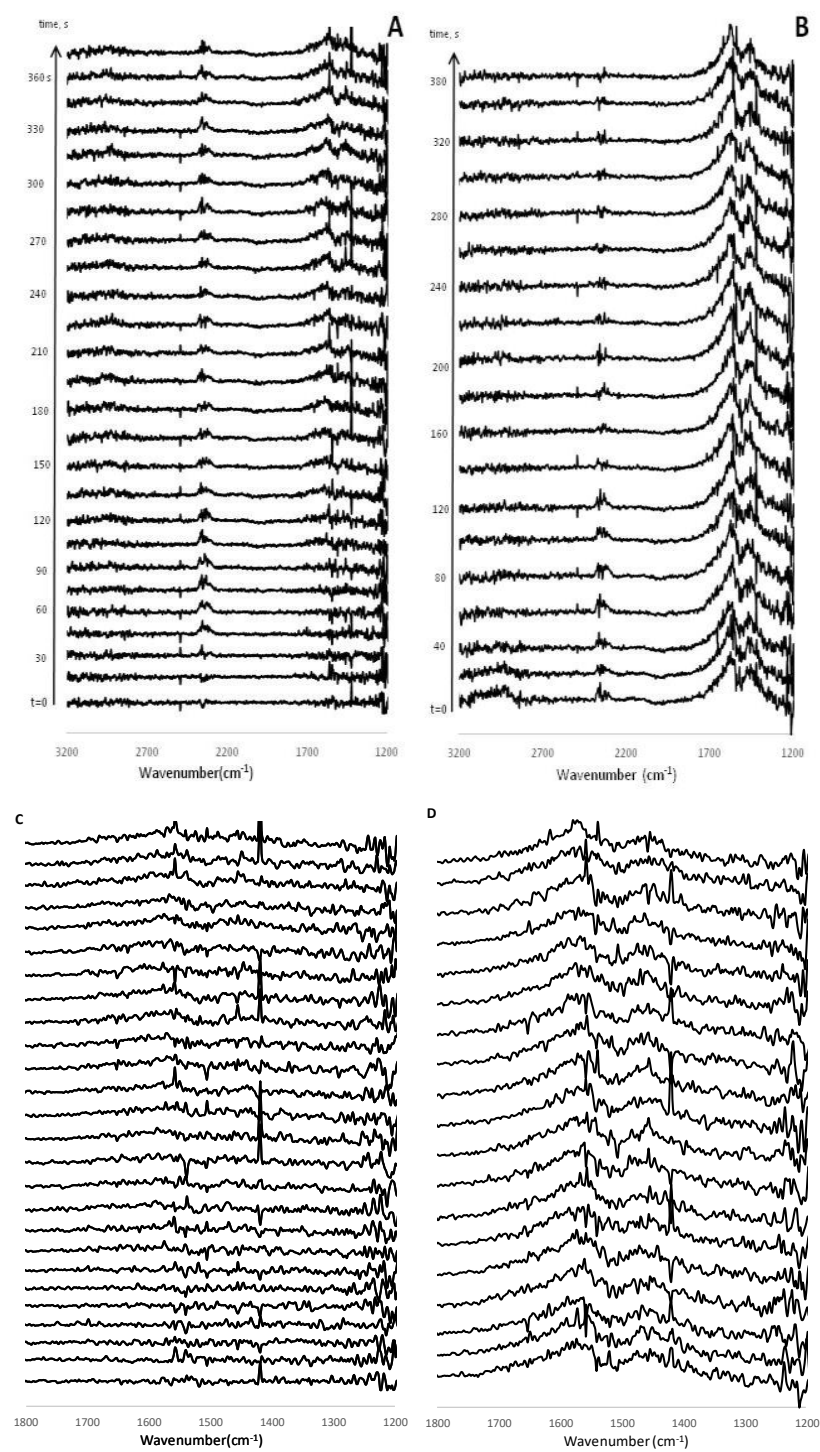

Figure 3A and 3B. Rapid scan spectra of $\mathrm{V} / \mathrm{Al}$ sample at $300^{\circ} \mathrm{C}$ immediately after the feed is changed air to $20 \%$ propylene/air (A) and vice-versa (B) during the first 6.5 minutes after the change. Spectrum has been taken every $15 \mathrm{seg}$ (A) and 20.5 (B). Figures 3C and 3D show an enlargement of the same spectra in the $1200-1800 \mathrm{~cm}^{-1}$ region.

\section{Ammoxidation of propane over V-Sb/Al catalyst}

Figure 4 shows DRIFTS spectra under different composition flows at $480^{\circ} \mathrm{C}$ for the $\mathrm{Sb}-\mathrm{V}-\mathrm{O} / \mathrm{Al}$ catalysts. When ammonia and air are feed at $480^{\circ} \mathrm{C}$, two bands are visible at 3332 and $1234 \mathrm{~cm}^{-1}$, that are characteristic of ammonia and assigned to $-\mathrm{N}-\mathrm{H}$ stretching and rocking, respectively. In addition, two bands are visible near 2220 and $2240 \mathrm{~cm}^{-1}$, with weaker modes around $1250 \mathrm{~cm}^{-1}$, that have been assigned to $\mathrm{N}_{2} \mathrm{O}\left({ }^{39}\right)$, indicative of ammonia partial oxidation. When propane and air are fed, bands near 2330 and $2382 \mathrm{~cm}^{-1}$ (characteristic of gaseous $\mathrm{CO}_{2}$ ) become clearly visible, along with two broad bands in the $1320-1520 \mathrm{~cm}^{-1}$ region that, as discussed previously, belong to formates/acetates that may form during propane oxidation. The position of the bands and the shape is not exactly the same when comparing spectra in Figures 1 and 4, due to the different reaction temperatures. Spectra under ammoxidation conditions show bands assigned to ammonia $\left(3332\right.$ and $1624 \mathrm{~cm}^{-1}$ ), and a band near $1470 \mathrm{~cm}^{-1}$ that resemble those detected under ODH conditions and are assigned to oxygenates, whereas $\mathrm{NOx}$ and $\mathrm{CO}_{2}$ bands are not visible and a band arises at $2170 \mathrm{~cm}^{-1}$, that can be assigned to the $-\mathrm{C} \equiv \mathrm{N}$ nitrile group $\left.{ }^{40}\right)$ and would indicate the formation of acrylonitrile. The presence under these conditions of $\mathrm{CO}_{2}, \mathrm{NOx}$ and acrylonitrile is in agreement with the on line MS analysis (Figure 5E). 


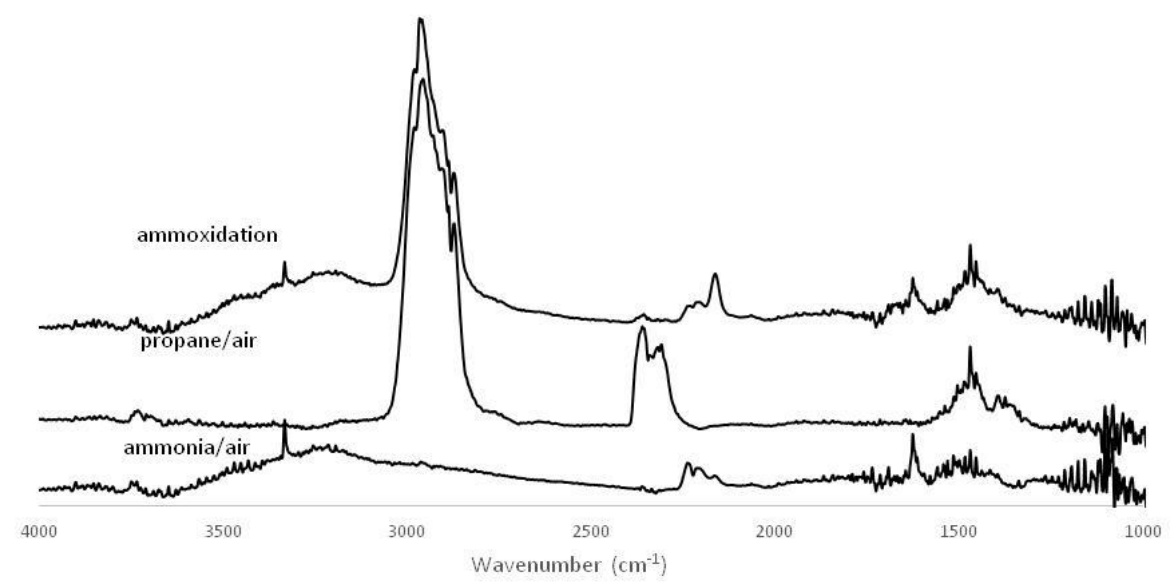

Figure 4. DRIFTS spectra of V-Sb-O/Al sample recorded at $480^{\circ} \mathrm{C}$, in propane/air (20\% propane in air), ammonia/air (10\% ammonia in air), ammoxidation conditions $\left(11 \% \mathrm{C}_{3} \mathrm{H}_{8}\right.$ and $9.5 \% \mathrm{NH}_{3}$ in air), and air. A background spectrum recorded in air was subtracted.

Rapid scan pulse experiments were performed in order to investigate the propane ammoxidation reaction mechanism. Firstly, ammonia pulses $(1 \mathrm{uL})$ were introduced in a propane/oxygen feed $(50 \mathrm{ml} / \mathrm{min})$. When propane oxidation was occurring, $\mathrm{CO}_{2}$ and propylene were detected, but after feeding the ammonia pulse, no acrylonitrile was detected, by either FTIR or MS. This indicates that when the surface sites are covered by adsorbed propane (reactive) or desorbing propylene (product) molecules due to the oxidation reaction, ammonia is not able to adsorb and the ammoxidation reaction cannot take place. This then indicates that nitrile insertion is not taking place in the gas phase and requires ammonia to be adsorbed. Previous DFT studies on rutile $\mathrm{SbVO}_{4}$ rutile phase (41-42-43) showed that the calculated energies of adsorption for ammonia and propane are quite similar on the $\mathrm{V}$ site of the rutile (around -32.8 for ammonia and $-30.8 \mathrm{kcal} / \mathrm{mol}$ for propane) which means that when the partial pressure of propane is high (propane/air flow), the ammonia pulse molecules are not able to displace propane molecules and subsequently the ammoxidation reaction to form acrylonitrile cannot take place. On the contrary, ammonia can adsorb on the $\mathrm{V}$ site of the rutile whereas propane can adsorb on the $\mathrm{V}$ site of the dispersed vanadium oxide phase, since the adsorption of propane is preferentially favored on these sites. This has previously been demonstrated since adsorbed alkoxide species on VOx sites were identified by operando Raman $\left({ }^{41}\right)$ and deuterium isotopic exchange demonstrates that propane activation occurs at its intermediate methylene carbon $\left({ }^{42}\right)$. Thus, the reaction was carried out in the opposite way and pure propane pulses were introduced into a $50 \mathrm{ml} / \mathrm{min}$ ammonia/oxygen flow with results shown in Figure 5. Figures 5A, B and C represent the intensity of the bands at 3000, 2240 and $2170 \mathrm{~cm}^{-1}$, respectively, versus time. The band at $3000 \mathrm{~cm}^{-1}$ is assigned to propane $(\mathrm{C}-\mathrm{H}$ stretch) and it is useful to locate the moment in which the pulse molecules are detected with respect the reaction products, in order to make a estimation around the required time to form those products, since in Figure 5, $t=0$ represents the moment at which the pulse was introduced into the flow through the 6-way valve. Figure 5D represents the propane and propylene mass fragment signals in the effluent as detected by MS. As can be observed, the fragments from propane and propylene are detected almost at the same time, indicating that the transformation of propane into propylene is almost instantaneous. Figure 5B represents the signal at 2240 $\mathrm{cm}^{-1}$ which corresponds to $\mathrm{N}_{2} \mathrm{O}\left({ }^{45}\right)$, the intensity of this signal decreases during the pulse and then recovers to the original intensity, in line with the MS spectrum, indicating that the oxidation of ammonia to $\mathrm{N}_{2} \mathrm{O}$ is not taking place when propane is in the feed, in line with previous ammoxidation studies that did not detected ammonia oxides under propane ammoxidation conditions (6). Figure 5C shows the intensity of the band at $2170 \mathrm{~cm}^{-1}$ that corresponds to acrylonitrile, which, as expected, appears during the propane ammoxidation reaction. The signal starts to increase and around 30 seconds after that the peak due to propane is detected. Since the MS signal of both acrylonitrile and $\mathrm{N}_{2} \mathrm{O}$ are quite low in comparison with propane, Figure E represents an enlargement of Figure D during the first 200 seconds. In line with the FTIR rapid scan results, the MS fragment corresponding to acrylonitrile is detected around 30 seconds after the peak of propylene. These rapid scan results demonstrate that the propane ammoxidation reaction over $\mathrm{Sb}-\mathrm{V}-\mathrm{O}$ catalysts occurs through two reaction steps, first, by propane dehydrogenation to propylene, and then the transformation of propylene intermediate into acrylonitrile, which is the limiting step. The formation of oxygenates was not detected during the first minutes, indicating that they are not 
intermediates during the propane transformation into acrylonitrile. The intensity of the bands assigned to oxygenates in the 1320-1520 $\mathrm{cm}^{-1}$ region during the propane pulse experiment are represented in Figure 6 and shows that no changes were detected during the first 100 seconds, in agreement with the propane oxidation experiments. These bands may appear due to secondary reactions through oxidation of propylene and remain adsorbed on the surface of the catalyst. These results are in agreement with theoretical DFT calculations over a Sb-V-O catalyst which indicated that the propane transformation into propylene occur on a VOx dispersed site $\left({ }^{43},{ }^{44},{ }^{45}\right)$ and the nitrogen insertion on the rutile $\mathrm{SbVO}_{4}$, in which the adsorption of ammonia was favored, being a mechanism with two reaction steps and two different active sites (redox for the propane dehydrogenation and acid for the ammonia adsorption). Both types of active sites were detected previously in Sb-V-O using methanol oxidation as test reaction $\left({ }^{46}\right)$.
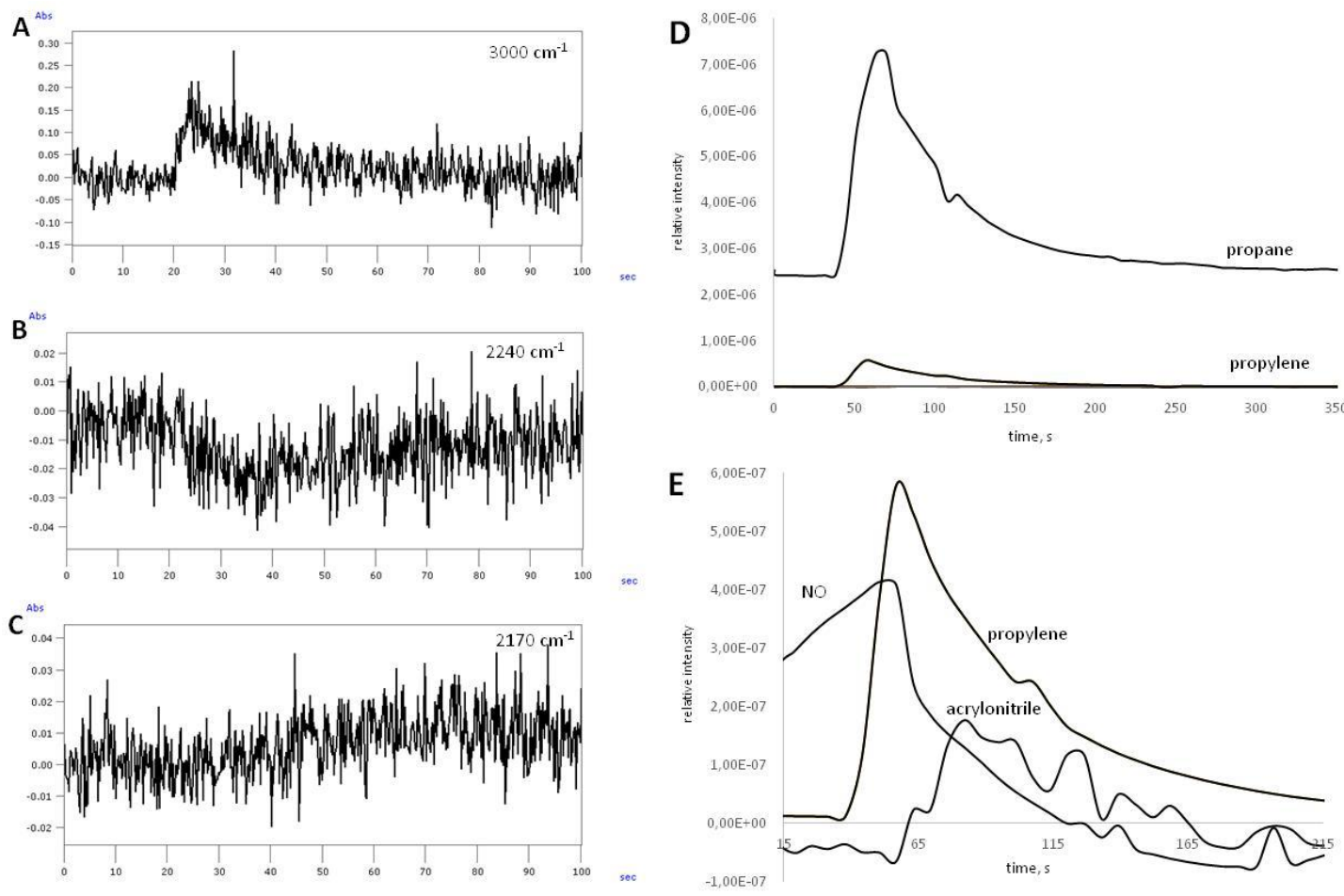

Figure 5. A, B, and C represent the intensity of the FTIR bands at $3000 \mathrm{~cm}^{-1}$ (A), $2240 \mathrm{~cm}^{-1}$ (B) and $2170 \mathrm{~cm}^{-1}$ (C) versus time after a pulse of $1 \mathrm{uL}$ propane over a $50 \mathrm{ml} / \mathrm{min} 9.5 \% \mathrm{NH}_{3}$ in air flow at $480^{\circ} \mathrm{C}$. Figures D and E represent the M.S. signals (FFT filtering was used for smoothing) for propane $(\mathrm{m} / \mathrm{e}=29)$, propylene $(\mathrm{m} / \mathrm{e}=41), \mathrm{NO}(\mathrm{m} / \mathrm{e}=30)$, and acrylonitrile $(\mathrm{m} / \mathrm{e}=53)$ during the same experiment (Figure $\mathrm{E}$ is an enlargement of Figure D). 

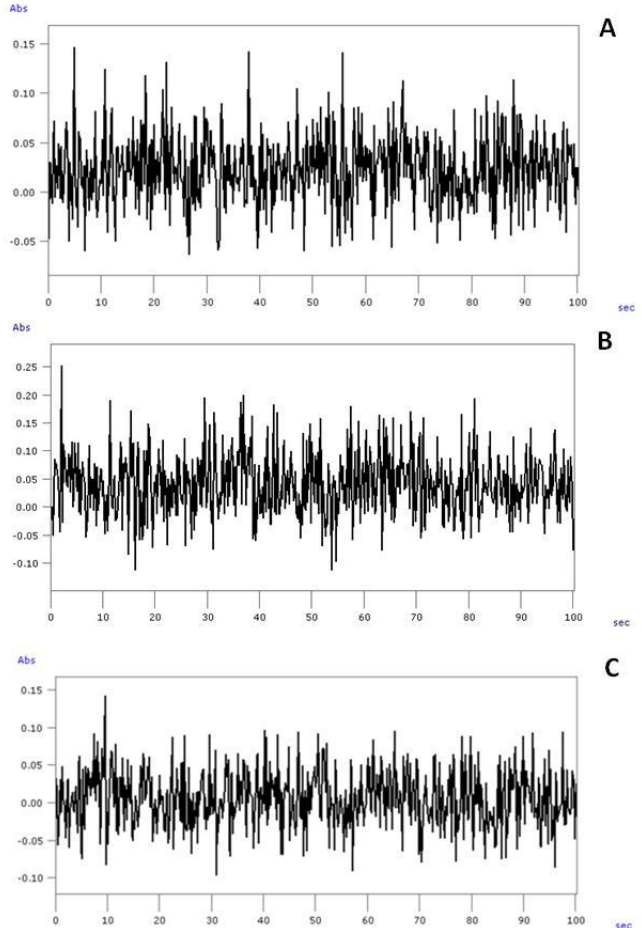

Figure 6. A, B, and C represent the intensity of the FTIR bands at $1360 \mathrm{~cm}^{-1}(\mathrm{~A}), 1470 \mathrm{~cm}^{-1}$ (B) and $1520 \mathrm{~cm}^{-1}(\mathrm{C})$ versus time after a pulse of $1 \mathrm{uL}$ propane over a $50 \mathrm{ml} / \mathrm{min} 9.5 \% \mathrm{NH}_{3}$ in air flow at $480^{\circ} \mathrm{C}$ (same experiment than Figure 5).

\section{Figures 5 and 6 here}

\section{Conclusions}

Rapid scan DRIFTS with on-line MS analysis has been applied for the elucidation of the mechanisms of propane oxidation and ammoxidation reactions with results demonstrating this is a useful technique for the identification of intermediates. By this manner, it has been possible to clarify some important aspects about which there was no clear agreement in literature. More specifically, the role of oxygenates during the propane oxidative dehydrogenation into propylene has been established, since rapid scan FTIR spectra have demonstrated that oxygenates are not formed during the initial stages of the reaction. Propane adsorbs on a VOx site and the transformation into propylene is very fast. Oxygenates (acetates, formates) may form through secondary reactions due to further oxidation of propylene. In the case of ammoxidation reaction, it was demonstrated that it occurs via two steps, firstly, propane dehydrogenates to propylene, and then propylene transforms into acrylonitrile, this later step being the rate limiting step.

\section{Acknowledgements}

MOGP acknowledges PRX17/00054 grant from Spanish Ministry of Education for performing a research stay at the University of Aberdeen. 


\section{References}

${ }^{1}$ R. Grabowski, Catal. Rev. Sci. Eng. 48 (2006) 199-268

${ }^{2}$ E. Heracleous, M. Machli, A.A. Lemonidou, I.A. Vasalos, J. Mol. Catal. A: Chem. 232 (2005) 29-39

${ }^{3}$ T. Blasco, J.M. López-Nieto, Appl. Catal. A: Gen. 157 (1997) 117-142

${ }^{4}$ M. Ai, J. Catal. 101 (1986) 389-395

${ }^{5}$ N. Mizuno, M. Tateishi, M. Iwamoto, Appl. Catal. A Gen. 128 (1995) L165-L170

${ }^{6}$ M.O. Guerrero-Pérez, J.L.G. Fierro, M.A. Vicente, M.A. Bañares, Chem. Mat. 19 (2007) 162-168

${ }^{7}$ J.F. Brazdil, Catal. Today in press (2020)

8 J. Dubois, U.S. Patent 8,829,223 (2014)

${ }^{9}$ M.O. Guerrero-Pérez, M.A. Bañares, ChemSusChem 1 (2008) 511-513

${ }^{10}$ E.M. Karp, T.R. Eaton, V. Sànchez i Nogué, V. Vorotnikov, M.J. Biddy, E.C.D. Tan, D.G. Brandner, R.M. Cywar, R. Liu, L.P. Manker, W.E. Michener, M. Gilhespy, Z. Skoufa, M.J. Watson, O. Stanley Fruchey, D.R. Vardon, R.T. Gill, A.D. Bratis, G.T. Beckham, Science 350 (2017) 1307-1310

${ }^{11}$ C. Liebiga, S. Paul, B. Katryniok, C. Guillon, J.L. Couturiere, J.L. Duboise, F. Dumeignil, W.F. Hoelderich, Appl. Catal. B: Environ. 132-133 (2013) 170-182

12 L.C. Kao, W.C. Kan, R.M. Martín-Aranda, M.O. Guerrero-Pérez, M.A. Bañares, S.Y.H. Liou, Catal. Today (2020) in press.

${ }^{13}$ M.O. Guerrero-Pérez, M.A. Bañares, Catal. Today 239 (2015) 25-30

${ }^{14}$ R.K. Grasselli, F. Trifirò, Top. Catal. 59 (2016) 1651-1658

${ }^{15}$ F. Cavani, N. Ballarini, A. Cericola, Catal. Today 127 (2007) 113-131

${ }^{16}$ A.M. Love, B. Thomas, S.E. Specht, M.P. Hanrahan, J.M. Venegas, S.P. Burt, J.T. Grant, M.C. Cendejas, W.P. McDermott, A.J. Rossini, I. Hermans, J. Am. Chem. Soc. 141 (2019) 182-190

${ }^{17}$ B. Mitra, I.E. Wachs, G. Deo, J. Catal. 240 (2006) 151-159

${ }^{18}$ A. Massó Ramírez, F. Ivars-Barceló, J.M. López-Nieto, Catal. Today (2019) in press.

${ }^{19}$ J. Haber, Catal. Today 142 (2009) 100-113

${ }^{20}$ M.O. Guerrero-Pérez, Catal. Today 285 (2017) 226-233

${ }^{21}$ G. Deo, I.E. Wachs, J. Catal. 146 (1994) 323-334

${ }^{22}$ I.E. Wachs, Dalton Trans. 42 (2013) 11762-11769

${ }^{23}$ Ch. Fabjan, J. Garche, B. Harrer, L. Jörissen, C. Kolbeck, F. Philippi, G. Tomazic, F. Wagner, Electrochim. Acta 47 (2001) 825-831

${ }^{24}$ M.O. Guerrero-Pérez, J.L.G. Fierro, M.A. Vicente, M.A. Bañares, J. Catal. 206 (2002) 339-348

${ }^{25}$ R. Nilsson, T. Lindblad, A. Andersson, J. Catal. 148 (1994) 501-513

${ }^{26}$ G. Centi, S. Perathoner, F. Trifirò, Appl. Catal. A. Gen. 157 (1997) 1233-1254

27 J.S. Kim, S.I. Woo, Appl. Catal. A 110 (1994) 173-184

${ }^{28}$ R.K. Grasselli, G. Centi, F. Trifiro, Appl. Catal. 57 (1990) 149-166

${ }^{29}$ P. Concepción, P. Botella, J.M. López Nieto, Appl. Catal. A.G Gen. 278 (2004) 45-56

${ }^{30}$ M.O. Guerrero-Pérez, M.A. Peña, J.L.G. Fierro, M.A. Bañares, Ind. Eng. Chem. Res. 45 (2006) 45374543

${ }^{31}$ A. Davó-Quiñonero, A. Bueno-López, D. Lozano-Castelló, A. J. McCue, J.A. Anderson, ChemCatChem 8 (2016) 1905-1908

${ }^{32}$ M.O. Guerrero-Pérez, J.L.G. Fierro, M.A. Bañares, Top. Catal. 41 (2006) 43

${ }^{33}$ S.M.K. Airaksinen, M.A. Bañares, A.O.I. Krause, J. Catal. 230 (2005) 507-513

${ }^{34}$ C.A. Carrero, R. Schloegl, I.E. Wachs, R. Schomaecker, ACS Catal. 4 (2014) 3357-3380

${ }^{35}$ G.L. Dai, Z.H. Li, J. Lu, W.N. Wang, K.N. Fan, J. Phys. Chem. C 116 (2012) 807-817

${ }^{36}$ D. Shee, G. Deo, J. Mol. Catal. A. Chem. 308 (2009) 46-55

${ }^{37}$ J.J. Ternero-Hidalgo, M.O. Guerrero-Pérez, J. Rodríguez-Mirasol, R. Cordero, M.A. Bañares, R. Portela,

P. Bazin, G. Clet, M. Daturi, Anal. Chem. 92 (2020) 5100-5106

${ }^{38}$ G. Liu, J.-J. Zho, T. Wu, L. Zeng, J. Gong, ACS Catal. 6 (2016) 5207-5214

39 J. Sá, J.A. Anderson, Appl. Catal. B: Environ. 77 (2008) 409-417

${ }^{40}$ G. Centi, F. Marchi, Stud. Surf. Sci. Cat. 101 (1996) 277-286

${ }^{41}$ M.O. Guerrero-Pérez, M.A. Bañares, Chem. Commun. (2002) 1292-1293

${ }^{42}$ L. Brazdil, A. Ebner, J.F. Brazdil, J. Catal. 163 (1996) 117-121

${ }^{43}$ E. Rojas, M. Calatayud, M.A. Bañares, M.O. Guerrero-Perez, J. Phys. Chem. C 116 (2012) 9132-9141

${ }^{44}$ E. Rojas, M. Calatayud, M.O. Guerrero-Pérez, M.A. Bañares, Catal. Today 158 (2010) 175-185 
${ }^{45}$ E. Rojas, M. Calatayud, M.O. Guerrero-Pérez, M.A. Bañares, Catal. Today 187 (2012) 212-213

${ }^{46}$ M.O. Guerrero-Pérez, T. Kim, M.A. Bañares, I.E. Wachs, J. Phys. Chem. C 112 (2008) 16858-16863 